\title{
The Development of Strategy Research: Evolution of Topics and Article Characteristics
}

\author{
David M. Brock \\ Ben-Gurion University of the Negev \\ E-Mail: dmb@som.bgu.ac.il \\ Ofer H. Azar \\ Ben-Gurion University of the Negev \\ E-Mail: azar@som.bgu.ac.il
}

\begin{abstract}
We analyze how the strategy field evolved between 1980-2004 by examining the topics of influential articles published in two of the field's most prominent journals, Long Range Planning (LRP) and the Strategic Management Journal (SMJ). Our findings describe the field's development, including declines in the traditional "content" and "process" categories, and increasing interest in topics related to firm resources and organizational issues. We also discuss changes in article characteristics - authorship, length and references - and reflect on how the strategy field has evolved over this early period in its development.
\end{abstract}

Keywords: Business Strategy, Development of Research, Strategic Management

\section{INTRODUCTION}

While humans have been practicing various forms of general and strategic management for as long as recorded history, the academic field of strategy research is still very young. Courses in strategic management-under various names like Administrative Strategy and Business Policy-were developed at many universities in the mid-1900s. However, it is barely 40 years since the onset of the field's legitimacy was heralded by the publication of Long Range Planning (LRP), and three decades since the appearance of the Strategic Management Journal (SMJ) and the Journal of Business Strategy (JBS). Although it is true that other fine management journals that 
considered the strategy area to be a part of their domains have been around for somewhat longer, these particular strategy journals signaled the independence of the strategy area, and proclaimed the importance of a space for the fledgling field's scholarly development.

Over these few decades the strategy field has matured. ${ }^{1}$ Several authors have grappled with trying to define the scope of the strategy field and what has influenced it—see for example, Evered (1983), Summer et al. (1990), Rumelt, Schendel and Teece (1994), Phelan, Ferreira and Salvador (2002), Nag, Hambrick, Chen (2007) and Hambrick and Chen (2008). Common approaches of these prior works have been collecting data from prominent scholars and counting "strategy" published in management journals. To date, however, there have been no studies regarding the important research topics published in strategy journals. Our approach in this article is to contribute to the understanding of the strategy field and how it has evolved by studying a selection of the most influential articles published in strategy journals during the field's formative years.

To achieve this we define and trace research topics as well as article characteristics in two of the field's leading journals, LRP and SMJ. We chose these journals as leaders in the two styles of academic publishing in the strategy area, with $L R P$ representing an applied, practitioner-oriented approach ${ }^{2}$ and $S M J$ representing a more theory-driven, academic-oriented approach. Our analysis does not include strategy research published in general management journals (much of which is top-quality and significant work), because we want to avoid the controversial and somewhat arbitrary decisions of which articles belong to the strategy field and which do not. By performing our analysis on two journals that focus on strategy, we can reasonably assume that any article they published can be considered a strategy article. Using data on highly-cited articles in LRP and SMJ, we analyze and discuss how the popularity of research topics and other article characteristics have changed over time.

The rest of the article is organized as follows. The next section presents the theoretical basis in several sections, each ending in hypothesis statements. After that the "data and methods" section reveals our various data sources; explains how we decided which journals and time periods to cover; describes how we tested the hypotheses; and generally presents our interpretations of the data as they reflect on the hypotheses as well as other relevant aspects of the development of strategy research.

\footnotetext{
${ }^{1}$ See Evered (1983) and Nag et al. (2007) for extended discussions of the history of the strategy field, how it developed, and how it may be defined.

${ }^{2}$ It should be noted that LRP reoriented itself towards a more scholarly approach in 2002. Because we analyze the period 1980-2004, however, $L R P$ generally represents the more applied approach to strategy research.
} 
The final section contains some concluding thoughts.

\section{HYPOTHESIS DEVELOPMENT}

\section{Content and Process Research}

It was clearly important for strategists at those early stages to define our major terms and frames of references. The centrality of and dichotomy between content research (e.g., Fahey and Christensen, 1986; Montgomery, 1988) and process research (e.g., Boal and Bryson, 1987; Huff and Reger, 1987) was thus stressed in early review articles in the nascent strategy field. Strategy content research concerns aspects of strategies (e.g., goals or specific competitive strategies like diversification) while strategy process research looks at how strategies are formed (including topics, like planning and decision making). Even more briefly, content research investigated the "What?" and process the "How?" of strategy. These are relatively core areas that are likely to dominate early academic research in the strategy field. Over time, however, one would expect that the focus of strategy research would broaden as coverage of these core issue increased and depending on contemporary economic, business and social trends. We suggest that most early strategy research would be classified into the content and process topics, but over time they would be succeeded by a broader range of topics.

H1: As the strategy field matures, there will be less emphasis on content and process research, and more emphasis on other topics.

\section{Practitioner and Scholarly Journals}

As mentioned earlier, there are a small number of strategy-specific journals. SMJ has maintained more of a scholarly research focus, while JBS has published more applied research, and meanwhile $L R P$ has shifted from an applied to a scholarly orientation. Several newer journals have entered the field, often by identifying the intersection between business strategy and another area as an important niche not yet served by existing journals. For example, the Journal of Economics \& Management Strategy - a significant, SSCI-indexed journal that was first published in 1992 - explicitly recognized the indispensable role of economics in strategic thinking. Similarly, Technology Analysis \& Strategic Management, which was established in 1989, and Business Strategy and the Environment, which started publishing in 1992, focused on the intersection of strategy with technological and environmental issues, respectively. Finally, Strategic Organization, established in 2003, seeks to integrate the strategy and organization studies fields. While excellent strategy research 
continues to be published in general management, organization studies, and economics journals, the journals mentioned above, being dedicated to strategy, play crucial roles in representing the field and by publishing much of the best research in strategic management.

Recalling the content-process terminology defined earlier, it is likely that content issues are more concrete than process issues, and thus easier to measure. Content research is thus more likely to be the subject of empirical research, and thus more likely to be published in scholarly journals, with process research more likely to appear in practitioner journals. Further, popular process topics like planning systems are inevitably popular with management consultants, key constituents of practitioner journals. However, as the strategy field matures and research methods become more refined, it is likely that more approaches will emerge for empirical research of strategy process issues, and thus this trend will likely dissipate.

H2a: The strategy process topic will be more popular in practitioner journals than in scholarly journals.

H2b: The difference mentioned above will diminish over time.

\section{Research Topics}

As an academic field matures it is natural for interest to broaden away from the core research topics (e.g., strategy content and process, in the strategy field) to newer topics, often seen as more relevant to the times. The first such topic to emerge in the strategy field was the resource-based view of the firm (RBV). Interest in this area by strategy researchers can be partially attributed to an article by Birger Wernerfelt (1984), which became the most-cited $S M J$ article to date ${ }^{3}$, and caused a significant paradigm shift in strategy research by popularizing the RBV of the firm. It is no coincidence that this period in history was one in which intangible assets-like corporate culture, knowledge, information systems, and dynamic capabilities-increasingly came to the attention of managers and researchers (Dougherty, 2004). The increasing importance of these resources thus caused us to ask more questions about how different kinds of resources—both tacit and explicit—may contribute to firm success (Grant, 1996; Kipping \& Engwall, 2002).

H3: There will be increasing interest in the "resources" topic over the 1980s and 1990s.

\footnotetext{
${ }^{3}$ Our analyses record 1,199 citations of this article (until June 2007) versus 929 of the second-placed Teece et al. (1997).
} 
The other research direction that has grown in popularity over the past few decades is an interest in various forms of organizations/firms. Most of the growth in this category over the years came from interest in cooperative relationships in general (e.g., Ring and Van de Ven, 1992); and in cooperative organizational forms like joint ventures (e.g., Doz, 1996) and networks (e.g., Dyer and Nobeoka, 2000; Gulati, Nohria and Zaheer, 2000). Researchers' increasing interest in these ever-complex organizational forms reflects the growing differentiation in organizational forms as firms compete in ever-freer and faster technology-enabled competition. The growth in this category thus reflects not only organizational developments but also strategy researchers' ability to theorize and operationalize these evolving constructs in an increasingly deregulated and boundary-less world.

H4: There will be increasing interest in the "firm types" topic over the 1980s and 1990s.

Ongoing and recurring fashions, fads, and other patterns in academic publishing have been well documented (e.g., Ellison, 2002a; Azar, 2007). Similarly, several authors (e.g., Hoskisson et al., 1999; Rumelt et al., 1994) have remarked on pendulum-like swings within the strategy field. A key aspect of these swings seem to be from a predominantly external focus - that followed Porter's (1980) popularization of analytic tools based on industrial-organization economics-towards the aforementioned internal focus on firm resources, competencies and intangible assets.

H5: Over time there will be swings in emphasis from external to internal perspectives of the strategy field.

\section{Article Characteristics}

As a research field grows we inevitably observe that more researchers enter the area. At the same time, research topics and methods become more specialized, and the database of articles on which to build theory and compare findings grows in depth as well as breadth. Observing the characteristics of journal articles over time, we would thus expect article length, the number of authors per article, and the number of references to increase. ${ }^{4}$

H6: Over time we could expect increasing article length, number of references, and number of authors per article in the strategy field.

\footnotetext{
${ }^{4}$ Similar trends were observed also in some other fields (Ellison, 2002b).
} 


\section{DATA AND METHODS}

\section{Citations}

One of the best indicators of whether a topic is significant to an academic discipline is the amount of times articles on this topic are cited in prominent journals. When an article is cited, it generally suggests that it has made some contribution to the literature on which the citing article builds, and so the number of citations that an article receives is a commonly-used indication of its significance. Citations are also an important measure of the quality and contribution of a scholar, an institution, or a journal. In addition, citation analysis allows to do "research on research" - to examine how the importance of different topics within a field changed over time, how much disciplines and areas within disciplines are related to each other, and so on.

The importance of citations for several purposes as explained above led to the creation of several databases that record citations in academic journals. ISI Web of Knowledge (henceforth ISI) and its "Web of Science" database, for example, continuously track thousands of journals in various disciplines and record all their citations. ${ }^{5}$ ISI also uses this database to compute the statistics reported in "Journal Citation Reports" (henceforth JCR), which includes several indicators of journal performance and quality, such as the impact factor and the total number of citations that a journal received in a given year from the other indexed journals.

\section{Data Used}

For a meaningful assessment of the development of the strategic management field, we decided to focus on journals that satisfy three criteria: they focus on strategic management, they are at least 25 years old (so that we may observe a meaningful development over time), and they are of high enough quality to be included in the Social Sciences Citation Index (SSCI). ${ }^{6}$ We limited attention to journals that deal entirely with strategic management and did not include strategy articles that appeared in general management journals. The reason is that including general management journals would require us to decide for each article whether it is about strategy or not. The results would then be sensitive to our personal opinions about what is strategy and to arbitrary decisions about what percentage of an article has to deal with strategy

\footnotetext{
5 The "Web of Science" database includes Science Citation Index Expanded, Social Sciences Citation Index, and Arts \& Humanities Citation Index.

${ }^{6}$ SSCI is a database that covers over 1,700 leading scholarly social sciences journals in more than 50 disciplines (see http://scientific.thomson.com/products/ssci/), including many in various areas of business administration and management. Inclusion in the SSCI database is an indication that the journal is above a certain quality threshold because SSCI includes only some of the journals of each discipline in its database, based on the journals' quality.
} 
in order to be classified as a strategy article. Only $L R P$ and $S M J$ satisfied the three conditions we indicated above and therefore the analysis below is devoted to these two journals. ${ }^{7}$

When choosing the period to be analyzed, 1980 was a natural starting point because this is the year in which SMJ commenced publication. Because we used citations to identify the most important strategy articles and because it takes time for articles to get cited, we did not include the years since 2005 in the analysis. The remaining period, 1980-2004, was divided to five consecutive periods of five years.

\section{Trends in Strategy Research Topics}

For the purpose of analyzing the trends in strategic concepts and research topics ${ }^{8}$, we studied in detail the 20 most-cited articles in each journal for each five-year period, for a total of 200 articles. $^{9}$ A list of seven categories of strategy research concepts was adapted from Nag et al. (2007), complemented with other common strategy research topics (for example, competitive strategy, planning, top management teams), and appears in Table 1 . We chose these classifications and not other classifications of the strategy field such as those presented by Summer et al. (1990) ${ }^{10}$ and Rumelt at al. (1994) ${ }^{11}$ because Nag et al. (2007) is more recent and comprehensive.

\footnotetext{
${ }^{7}$ The only two journals that satisfy the conditions of focusing on strategy and being in SSCI (other than LRP and SMJ) are the Journal of Economics \& Management Strategy and Technology Analysis \& Strategic Management. In addition to being established for too little time for our purposes (and covered by SSCI for even a shorter period), both journals are not general-interest strategy journals, but rather focus on a specific niche of strategy research.

${ }^{8}$ On the evolution of strategic management research see also Ramos-Rodriguez and Ruiz-Navarro (2004).

${ }^{9}$ The full list of 100 top-cited articles for each journal is available from the authors.

${ }^{10}$ The four conceptual domains to the strategy field are defined as: environment, strategy (content), leadership/organization, and performance.

${ }^{11}$ Four "fundamental issues" are presented as questions: How do firms behave? Why are firms different? What is the function/value of headquarters? What determines success/failure in international competition?
} 


\section{Table 1 Strategy Research Topics}

\section{Strategy content}

Competitive strategy, diversification, scale/scope, acquisition, entry mode (e.g., greenfield, joint venture), positioning

\section{Strategy process}

Planning, innovation, learning, structuring, alliance formation, implementation, scenarios, forecasting, environmental scanning

\section{Strategy actors}

TMT (top management teams), boards, CEO, compensation, agency and director responsibility, mechanisms of firm governance and ownership

4. Resources

Stock, capability, technology, slack, knowledge, information technology

\section{Performance}

Growth, returns, decline, dominance, profits, sustainability, competitive advantage

\section{Organization/firm type}

Corporate, SBU, subsidiary, networks, alliance

\section{External environment}

Competition, market, contingency, threats, strategic groups

Comment: The concepts are adapted from Nag et al. (2007), Tables 2 and 5.

Then, the 100 most-cited articles in each journal were analyzed and classified, with each article to primary and secondary topics. ${ }^{12}$ Table 2 presents these classifications. The "Primary and secondary" columns on the right sum the number of times that a category appeared as either the primary or the secondary topic of an article. Assigning a greater weight to the primary topics when aggregating them with the secondary topics did not have a consistently significant effect on any of the trends and relative levels detected. Table 2 has three parts: Table 2A includes the 100 LRP articles, Table 2B includes the 100 SMJ articles, and Table 2C combines all 200 of the most-cited articles from both journals.

Each table shows the topics of the 20 most-cited articles in the relevant journal/s in each of the five periods we analyzed. Thus the first (top-left in Table 2A) number "2" implies that two of the top-20 LRP articles in the 1980-1984 period were classified as having a primary focus within the "Strategy content" category.

The next step was to analyze these data, specifically checking for significant

\footnotetext{
${ }^{12}$ We classified as "primary" the topic within which the paper made its main impact and as "secondary" the next most important topic. Thus each of the 100 papers per journal received two classifications, giving totals of 200 in the "Primary and secondary" columns in Tables 2A and 2B (and 400 in Table 2C).
} 
changes in the topics of the articles in the two journals. Most of the hypotheses examined trends in the various categories of research presented in Table 2 (content, process, etc.). Thus we chose a simple yet clear way to perform the tests, namely combing the data (in each category) for the first and last ten years (1980-89, 1995-2004) and comparing the difference in the number of times that each topic appeared in the two periods using chi-square tests. The results (expressed as $\chi^{2}$ values and $p$-values) indicate whether there are significant increases or decreases in the various research categories over the years. The results of these analyses are presented in Table 3. Once again the table is presented in three parts: Table 3A for the LRP articles, Table 3B for SMJ, and Table 3C combining articles from both journals.

The $\chi^{2}$ tests were performed on each category separately by comparing the number of observations in the category to the combined number of observations not in that category. Therefore, for Tables 3A and 3B the statistical tests have d.f. $=1$ and $N$ $=160$ (primary and secondary classifications) or 80 (primary classifications only). For Table 3C all the statistical tests have d.f. $=1$ and $N=320$ (primary and secondary classifications) or 160 (primary classifications only). The statistical tests were omitted when the number of observations was too small for a meaningful test.

Not only do these data and statistical tests paint fascinating pictures of developments within the strategy field, but also theory lends substantial support to our hypotheses. We will discuss the results under the same sub-headings by which the hypotheses were presented.

\section{Content and Process Research}

The centrality of concepts like competitive strategy, diversification, planning and implementation in the early years is reflected in the observation that over half the articles we analyzed in both journals in the 1980s address topics that belong to categories 1 and 2-namely strategy content and process research. Table 3 confirms - regardless of whether we look just at the primary classifications or at the combined primary and secondary classifications - several observations apparent from Table 2 about the evolution of research topics in these highly-cited articles. As hypothesized (H1), there is generally a decline in categories 1 and 2. Specific statistical tests show significant declines in process research in LRP (Table 3A), significant declines in content research in SMJ (Table 3B), and significant declines in both categories for the combined sample (Table 3C). In the cases where the statistical tests were not statistically significant (content in LRP and process in $S M J$ ), they were still in the direction of declining interest in content and process research. 
Table 2A Research Topics of the Most-Cited Articles in Long Range Planning

\section{Primary}

\begin{tabular}{|c|c|c|c|c|c|c|}
\hline Category $\quad$ Period & 80-84 & 85-89 & $90-94$ & $95-99$ & 00-04 & Total \\
\hline 1: Strategy content & 2 & 2 & 5 & 1 & 0 & 10 \\
\hline 2: Strategy process & 17 & 16 & 13 & 8 & 13 & 67 \\
\hline 3: Strategy actors & 0 & 0 & 0 & 0 & 0 & 0 \\
\hline 4: Resources & 0 & 1 & 0 & 6 & 3 & 10 \\
\hline 5: Performance & 0 & 0 & 0 & 1 & 1 & 2 \\
\hline 6: Organization/firm type & 1 & 1 & 1 & 4 & 2 & 9 \\
\hline 7: External environment & 0 & 0 & 1 & 0 & 1 & 2 \\
\hline Total & 20 & 20 & 20 & 20 & 20 & 100 \\
\hline
\end{tabular}

Table 2A Research Topics of the Most-Cited Articles in Long Range Planning (Continued)

\begin{tabular}{|c|c|c|c|c|c|c|}
\hline \multirow[b]{2}{*}{ Category } & \multicolumn{6}{|c|}{ Primary and secondary } \\
\hline & $80-84$ & 85- 89 & $90-94$ & 95-99 & 00-04 & Total \\
\hline 1: Strategy content & 4 & 4 & 10 & 1 & 0 & 19 \\
\hline 2: Strategy process & 25 & 23 & 17 & 17 & 18 & 100 \\
\hline 3: Strategy actors & 1 & 0 & 2 & 1 & 3 & 7 \\
\hline 4: Resources & 0 & 5 & 4 & 11 & 8 & 28 \\
\hline 5: Performance & 1 & 4 & 1 & 5 & 2 & 13 \\
\hline 6: Organization/firm type & 2 & 2 & 2 & 4 & 4 & 14 \\
\hline 7: External environment & 7 & 2 & 4 & 1 & 5 & 19 \\
\hline Total & 40 & 40 & 40 & 40 & 40 & 200 \\
\hline
\end{tabular}


Table 2B Research Topics of the Most-Cited Articles in the Strategic Management Journal

\begin{tabular}{lcccccc}
\hline & \multicolumn{7}{c}{ Primary } \\
\hline Category & $\mathbf{8 0 - 8 4}$ & $\mathbf{8 5 - 8 9}$ & $\mathbf{9 0 - 9 4}$ & $\mathbf{9 5 - 9 9}$ & $\mathbf{0 0 - 0 4}$ & Total \\
\hline 1: Strategy content & 3 & 7 & 1 & 0 & 0 & $\mathbf{1 1}$ \\
\hline 2: Strategy process & 10 & 4 & 3 & 6 & 4 & $\mathbf{2 7}$ \\
\hline 3: Strategy actors & 0 & 1 & 0 & 0 & 0 & $\mathbf{1}$ \\
\hline 4: Resources & 1 & 0 & 9 & 6 & 6 & $\mathbf{2 2}$ \\
\hline 5: Performance & 5 & 3 & 0 & 3 & 3 & $\mathbf{1 4}$ \\
\hline 6: Organization/firm type & 0 & 3 & 5 & 3 & 7 & $\mathbf{1 8}$ \\
\hline 7: External environment & 1 & 2 & 2 & 2 & 0 & $\mathbf{7}$ \\
\hline Total & 20 & 20 & 20 & 20 & 20 & $\mathbf{1 0 0}$ \\
\hline
\end{tabular}

Table 2B Research Topics of the Most-Cited Articles in the Strategic Management Journal (Continued)

\begin{tabular}{lcccccc}
\hline & \multicolumn{7}{c}{ Primary and secondary } \\
\hline Category & $\mathbf{8 0 - 8 4}$ & $\mathbf{8 5 - 8 9}$ & $\mathbf{9 0 - 9 4}$ & $\mathbf{9 5 - 9 9}$ & $\mathbf{0 0 - 0 4}$ & Total \\
\hline 1: Strategy content & 8 & 9 & 5 & 0 & 0 & $\mathbf{2 2}$ \\
\hline 2: Strategy process & 15 & 9 & 12 & 10 & 7 & $\mathbf{5 3}$ \\
\hline 3: Strategy actors & 1 & 2 & 0 & 0 & 1 & $\mathbf{4}$ \\
\hline 4: Resources & 2 & 1 & 9 & 12 & 11 & 35 \\
\hline 5: Performance & 8 & 8 & 4 & 8 & 9 & 37 \\
\hline 6: Organization/firm type & 2 & 4 & 6 & 7 & 10 & $\mathbf{2 9}$ \\
\hline 7: External environment & 4 & 7 & 4 & 3 & 2 & $\mathbf{2 0}$ \\
\hline Total & 40 & 40 & 40 & 40 & 40 & $\mathbf{2 0 0}$ \\
\hline
\end{tabular}


Table 2C Research Topics of the Most-Cited Articles: Combined Sample of $L R P$ and $S M J$

\begin{tabular}{lcccccc}
\hline & \multicolumn{7}{c}{ Primary } \\
\hline Category & $\mathbf{8 0 - 8 4}$ & $\mathbf{8 5 - 8 9}$ & $\mathbf{9 0 - 9 4}$ & $\mathbf{9 5 - 9 9}$ & $\mathbf{0 0 - 0 4}$ & Total \\
\hline 1: Strategy content & 5 & 9 & 6 & 1 & 0 & $\mathbf{2 1}$ \\
\hline 2: Strategy process & 27 & 20 & 16 & 14 & 17 & $\mathbf{9 4}$ \\
\hline 3: Strategy actors & 0 & 1 & 0 & 0 & 0 & $\mathbf{1}$ \\
\hline 4: Resources & 1 & 1 & 9 & 12 & 9 & $\mathbf{3 2}$ \\
\hline 5: Performance & 5 & 3 & 0 & 4 & 4 & $\mathbf{1 6}$ \\
\hline 6: Organization/firm type & 1 & 4 & 6 & 7 & 9 & $\mathbf{2 7}$ \\
\hline 7: External environment & 1 & 2 & 3 & 2 & 1 & $\mathbf{9}$ \\
\hline Total & 40 & 40 & 40 & 40 & 40 & $\mathbf{2 0 0}$ \\
\hline
\end{tabular}

Table 2C Research Topics of the Most-Cited Articles: Combined Sample of LRP and SMJ (Continued)

\begin{tabular}{lccccccc}
\hline & \multicolumn{7}{c}{ Primary and secondary } \\
\cline { 1 - 7 } Category & Period & $\mathbf{8 0 - 8 4}$ & $\mathbf{8 5 - 8 9}$ & $\mathbf{9 0 - 9 4}$ & $\mathbf{9 5 - 9 9}$ & $\mathbf{0 0 - 0 4}$ & Total \\
\hline 1: Strategy content & 12 & 13 & 15 & 1 & 0 & $\mathbf{4 1}$ \\
\hline 2: Strategy process & 40 & 32 & 29 & 27 & 25 & $\mathbf{1 5 3}$ \\
\hline 3: Strategy actors & 2 & 2 & 2 & 1 & 4 & $\mathbf{1 1}$ \\
\hline 4: Resources & 2 & 6 & 12 & 23 & 19 & $\mathbf{6 3}$ \\
\hline 5: Performance & 9 & 12 & 5 & 13 & 11 & $\mathbf{5 0}$ \\
\hline 6: Organization/firm type & 4 & 6 & 8 & 11 & 14 & $\mathbf{4 3}$ \\
\hline 7: External environment & 11 & 9 & 8 & 4 & 7 & $\mathbf{3 9}$ \\
\hline Total & 80 & 80 & 80 & 80 & 80 & $\mathbf{4 0 0}$ \\
\hline
\end{tabular}


Table 3A Statistical Tests of Trends in Research Topics in Long Range Planning

\begin{tabular}{lcccccccc}
\hline & \multicolumn{3}{c}{ Primary and secondary classifications } & \multicolumn{3}{c}{ Primary classifications only } \\
\hline & $80-89$ & $95-04$ & $\chi^{2}$ value & $p$-value & $80-89$ & $95-04$ & $\chi^{2}$ value & $p$-value \\
\hline 1: Strategy content & 8 & 1 & 5.77 & 0.0163 & 4 & 1 & 1.92 & 0.1659 \\
\hline 2: Strategy process & 48 & 35 & 4.23 & 0.0397 & 33 & 21 & 8.21 & 0.0042 \\
\hline 3: Strategy actors & 1 & 4 & 1.86 & 0.1728 & 0 & 0 & & \\
\hline 4: Resources & 5 & 19 & 9.61 & 0.0019 & 1 & 9 & 7.31 & 0.0068 \\
\hline 5: Performance & 5 & 7 & 0.36 & 0.5483 & 0 & 2 & & \\
\hline $\begin{array}{l}\text { 6: Organization/ } \\
\text { firm type }\end{array}$ & 4 & 8 & 1.44 & 0.2299 & 2 & 6 & 2.22 & 0.1360 \\
\hline $\begin{array}{l}\text { 7: External } \\
\text { environment }\end{array}$ & 9 & 6 & 0.66 & 0.4158 & 0 & 1 & & \\
\hline Total & 80 & 80 & & & 40 & 40 & & \\
\hline
\end{tabular}

Table 3B Statistical Tests of Trends in Research Topics in the Strategic Management Journal

\begin{tabular}{lcccccccc}
\hline & \multicolumn{3}{c}{ Primary and secondary classifications } & \multicolumn{3}{c}{ Primary classifications only } \\
\hline & $80-89$ & $95-04$ & $\chi^{2}$ value & $p$-value & $80-89$ & $95-04$ & $\chi^{2}$ value & $p$-value \\
\hline 1: Strategy content & 17 & 0 & 19.02 & 0.0000 & 10 & 0 & 11.43 & 0.0007 \\
\hline 2: Strategy process & 24 & 17 & 1.61 & 0.2049 & 14 & 10 & 0.95 & 0.3291 \\
\hline 3: Strategy actors & 3 & 1 & 1.03 & 0.3112 & 1 & 0 & & \\
\hline 4: Resources & 3 & 23 & 18.37 & 0.0000 & 1 & 12 & 11.11 & 0.0009 \\
\hline 5: Performance & 16 & 17 & 0.04 & 0.8451 & 8 & 6 & 0.35 & 0.5562 \\
\hline $\begin{array}{l}\text { 6: Organization/ } \\
\text { firm type }\end{array}$ & 6 & 17 & 6.14 & 0.0132 & 3 & 10 & 4.50 & 0.0339 \\
\hline $\begin{array}{l}\text { 7: External } \\
\text { environment }\end{array}$ & 11 & 5 & 2.50 & 0.1138 & 3 & 2 & 0.21 & 0.6442 \\
\hline Total & 80 & 80 & & & 40 & 40 & & \\
\hline
\end{tabular}


Table 3C Statistical Tests of Trends in Research Topics - Combined Sample of LRP and $S M J$

\begin{tabular}{lcccccccc}
\hline & \multicolumn{1}{c}{ Primary and secondary classifications } & \multicolumn{3}{c}{ Primary classifications only } \\
\hline & $80-89$ & $95-04$ & $\chi^{2}$ value & $p$-value & $80-89$ & $95-04$ & $\chi^{2}$ value & $p$-value \\
\hline 1: Strategy content & 25 & 1 & 24.11 & 0.0000 & 14 & 1 & 12.43 & 0.0004 \\
\hline 2: Strategy process & 72 & 52 & 5.27 & 0.0217 & 47 & 31 & 6.40 & 0.0114 \\
\hline 3: Strategy actors & 4 & 5 & 0.11 & 0.7353 & 1 & 0 & & \\
\hline 4: Resources & 8 & 42 & 27.40 & 0.0000 & 2 & 21 & 18.33 & 0.0000 \\
\hline 5: Performance & 21 & 24 & 0.23 & 0.6295 & 8 & 8 & 0.00 & 1.0000 \\
\hline $\begin{array}{l}\text { 6: Organization/ } \\
\text { firm type }\end{array}$ & 10 & 25 & 7.22 & 0.0072 & 5 & 16 & 6.63 & 0.0100 \\
\hline $\begin{array}{l}\text { 7: External } \\
\text { environment }\end{array}$ & 20 & 11 & 2.89 & 0.0890 & 3 & 3 & 0.00 & 1.0000 \\
\hline Total & 160 & 160 & & & 80 & 80 & & \\
\hline
\end{tabular}

\section{Practitioner and Scholarly Journals}

In order to examine $\mathrm{H} 2 \mathrm{a}$ and $\mathrm{H} 2 \mathrm{~b}$ we compared the numbers of articles (Table $2 \mathrm{~A}$ versus $2 \mathrm{~B}$ ) and the trends (Tables $3 \mathrm{~A}$ versus $3 \mathrm{~B}$ ) in the content and process categories for the two journals; the results illustrate a fascinating picture of the development of strategy research. A large percentage of $L R P$ articles-over $80 \%$ in the 1980s and about 50\% in the 1990s — had a primary focus on the strategy process. In the 1980s these included many articles on environmental scanning, scenarios, and other strategic planning tools. These were clearly topics of relevance and importance to strategists of that era, representing fairly practical and basic tools for strategic analysis and strategy formulation. By the 1990s, however, strategists were ready for a broader variety of approaches to organizational and managerial issues and to functional processes-and this is reflected in our analysis: Looking at the "Primary and secondary" columns for $L R P$ (Table 2A), the strategy process category accounts for $60 \%$ of the total in the 1980 s and $43 \%$ in the $1990-2004$ period. LRP articles classified either primarily or secondarily as "strategy content," on the other hand, were less than ten percent of the total for the entire period. This indicated that the relatively basic classification- and contingency-based research had served its purpose, and strategists were moving on to more complex topics.

Similar to the results in $L R P$, the biggest category in the $S M J$ was also strategy process ( $26.5 \%$ of total). The downward trends in this category between the first and 
last decade studied are apparent in all cases, but statistically significant only for $L R P$ and the combined LRP-SMJ sample (see Table 3). The declining trend in category 1, "strategy content," was highly statistically significant for the SMJ and the combined sample, and for LRP when secondary classification was also taken into consideration. ${ }^{13}$ Thus, LRP and SMJ played complementary roles in the establishment of the strategy field with respect to content and process research: both journals published many articles in the 1980s on strategic planning tools and fewer in the content category, but with both categories declining into the new millennium. Their varying emphases on practitioner and scholarly research were thus complementary in the building of the research and knowledge bases for the strategy field.

\section{Research Topics}

Considering the combined sample, the second most popular research area was "Resources" (category 4). As mentioned earlier, the Wernerfelt (1984) article in SMJ contributed to the popularity of the RBV, and it grew to be a significant area within the management field in general. The huge impact of the RBV is illustrated by the significantly increasing trend in category 4 in both $L R P$ and $S M J$, irrespective of whether we use also the secondary classification or not (see Tables 3A and 3B). Thus, while resources accounted for about $16 \%$ of the total category classifications in the combined sample over the 25-year period, the figure rises to over $26 \%$ for the decade 1995-2004. As Table 3 demonstrates, both journals showed significant increases in this category over time. These data clearly support H3.

Apart from resources, the other topic to enjoy ascendancy over our 25-year survey of the field was the category of organization/firm type (category 6). As discussed earlier, there has been a growing interest in joint ventures, networks, and other cooperative ventures. The trend is positive and statistically significant for the SMJ and the combined sample (Table 3B and 3C). In this category the unit of analysis itself became the object of study. These data clearly support $\mathrm{H} 4$.

Further, our data seem to support the "swings" in research emphasis over time as argued ahead of H5. For example, if we take the "resources" category as representing the internal focus, we see it move (in Table 2C) quite opposite to the "external environment" category: To wit, the latter peaks and the former troughs in the 1980-84 period; then the former peaks while the latter troughs in 1995-99. Future studies will reveal whether the pendulum swings back in the direction of the external environment

\footnotetext{
${ }^{13}$ When only primary classifications are considered in $L R P$, the sharp relative decline in this category, from four articles in 1980-1989 to one in 1995-2004 (see Table 3A), is not statistically significant due to the small number of observations.
} 
or the trend perhaps continues in another direction.

Finally, it is interesting to consider the trends (or lack thereof) in other topics. Considering the total number of classifications (both primary and secondary), category 5 (performance) was third in popularity in the combined sample, revealing the perennial and consistent interest that strategy researchers have in topics like profitability, growth, and firm survival. Articles belonging to this category often follow a common research model (outlined, for example, by Ginsberg and Venkaraman, 1985) whereby the performance implications of some strategy or strategic process would be tested. Typical examples of such articles are Rumelt (1982) and Prahalad and Bettis (1986) both of which tested the relationship between diversification and profitability.

The two categories that appear less frequently in the most-cited articles, especially when considering only the primary classification, are nevertheless absolutely central to the strategy field. For example, Nag et al. (2007) and Rumelt at al. (1994) both include strategy actors (category 3) as a major topic in the strategy field; and similarly, Summer et al. (1990) emphasize the external environment (category 7). Even though our analyses show that they appear relatively little as the main topics of the most-cited articles in $L R P$ and $S M J$, it may be that other management journals that favor more micro/individual-level research such as the Academy of Management's publications or macro/environmental-level work such as Business Strategy and the Environment are more likely to publish these topics than either $L R P$ or $S M J$. Future research to examine these issues would certainly be appropriate.

\section{Trends in Article Characteristics}

In addition to analyzing the topics of the most influential $L R P$ and $S M J$ articles, we also argued above (ahead of H6) and examined whether other article characteristics changed over the years. The analysis was performed on all the articles published in LRP and the SMJ over the period 1980-2004; in total, the analysis includes 1,692 LRP articles and 1,301 SMJ articles. ${ }^{14}$ Table 4 reports the trends in article characteristics over this period. The change in LRP's editorial policy towards a more scholarly orientation in 2002 (mentioned above) is clearly one factor (at least, for the final two years of our data) in precipitating longer articles and more references. Other factors and issues relevant to the development of the field are discussed below.

\footnotetext{
${ }^{14}$ The data were taken from Social Science Citation Index (SSCI). We included in the analysis publications of type of article, note, and review. Publication types of correction, addition, book review, biographical item, and editorial material were excluded.
} 
We can see in Table 4 several trends, all of which are common to both journals. ${ }^{15}$ One is that papers became longer over the years: in LRP the length of the average article increased from 8.7 pages in 1980-1984 to 19.3 in 2000-2004, an increase of $121 \%$. In the $S M J$ the average article length increased over the same period by $28 \%$, from 13.5 to 17.3 pages. While in the $S M J$ the increase is gradual, in $L R P$ the article length increases very little until 1999, and then between the period 1995-1999 and 2000-2004 it more than doubles. The reason for the dramatic increase in LRP seems to be a change in editorial policy, to publish fewer yet longer articles. Additional potential reasons for the trend in both journals are that the level of statistical analysis of data has become more elaborate over time; that the datasets used today are richer than in the past, allowing for more analysis; and that the coverage of the literature is more extensive nowadays and therefore requires more space.

The prior observation is related to another trend - the increase in the number of references. In $L R P$ the average number of references increased from 11.2 in $1980-1984$ to 30.8 in 2000-2004, an increase of $176 \%$; in the $S M J$ it increased by $144 \%$, from 25.9 in $1980-1984$ to 63.1 in 2000-2004. These increases can be attributed to several possible reasons. First, the extent of previous literature (for example, the number of previously-published articles in a certain topic) obviously increases over time, thus creating a larger number of relevant articles to cite. It is also possible that the norm about how extensive the literature review should be has changed over the years and today authors are expected to write a more detailed literature review than in the past, resulting in more references being cited. It is interesting to point out that Ellison (2002b) documents an increase in the number of pages (between 1975 and 1999) and the number of references (between 1977/78 and 1998) in many journals in other disciplines, although in some journals he finds an opposite trend.

A third trend is towards more authors on each paper: the average number of authors increased in LRP from 1.31 in 1980-1984 to 2.18 in 2000-2004, an increase of $66 \%$, and in the $S M J$ it increased over the same period by $39 \%$, from 1.50 to 2.09 . We propose two possible explanations for this trend. One is the advance of telecommunications and the Internet. E-mail makes collaboration with others who are not located in the same institution much easier, and can thus make collaboration more efficient and lead to an increasing number of co-authors in the average paper. A second potential explanation is that the increased sophistication of research over time in terms of statistical methods, richness of datasets, etc., might imply that it is

${ }^{15}$ See also Phelan et al. (2002), who compare characteristics of SMJ articles in the years 1980 and 1999. 
increasingly more challenging for a single author to perform well all the tasks involved in writing a high-quality article, and therefore more researchers are involved in a typical study than in the past.

Table 4A Characteristics of Articles in Long Range Planning

\begin{tabular}{|c|c|c|c|c|c|}
\hline & 1980-1984 & 1985-1989 & 1990-1994 & 1995-1999 & 2000-2004 \\
\hline Number of articles & 370 & 416 & 397 & 367 & 142 \\
\hline \multicolumn{6}{|l|}{ Number of pages } \\
\hline Average & 8.7 & 7.9 & 8.8 & 9.5 & 19.3 \\
\hline Minimum & 2 & 1 & 2 & 1 & 3 \\
\hline 25th percentile & 6 & 6 & 7 & 8 & 16 \\
\hline Median & 8 & 8 & 9 & 10 & 19 \\
\hline 75th percentile & 10 & 9 & 11 & 12 & 23 \\
\hline Maximum & 35 & 21 & 24 & 21 & 30 \\
\hline Standard deviation & 4.3 & 2.8 & 3.1 & 3.2 & 5.2 \\
\hline \multicolumn{6}{|c|}{ Number of references } \\
\hline Average & 11.2 & 10.9 & 13.2 & 18.8 & 30.8 \\
\hline Minimum & 0 & 0 & 0 & 0 & 0 \\
\hline 25th percentile & 1 & 0 & 3 & 7 & 20 \\
\hline Median & 7 & 7 & 11 & 16 & 30 \\
\hline 75th percentile & 16 & 15 & 20 & 25 & 42 \\
\hline Maximum & 172 & 113 & 64 & 85 & 86 \\
\hline Standard deviation & 14.5 & 13.8 & 11.6 & 15.6 & 16.1 \\
\hline \multicolumn{6}{|l|}{ Number of authors } \\
\hline Average & 1.31 & 1.38 & 1.50 & 1.62 & 2.18 \\
\hline Minimum & 1 & 1 & 1 & 1 & 1 \\
\hline 25th percentile & 1 & 1 & 1 & 1 & 2 \\
\hline Median & 1 & 1 & 1 & 1 & 2 \\
\hline 75th percentile & 2 & 2 & 2 & 2 & 3 \\
\hline Maximum & 4 & 5 & 5 & 7 & 8 \\
\hline Standard deviation & 0.58 & 0.64 & 0.70 & 0.82 & 1.00 \\
\hline
\end{tabular}


Table 4B Characteristics of Articles in the Strategic Management Journal

\begin{tabular}{|c|c|c|c|c|c|}
\hline & 1980-1984 & 1985-1989 & 1990-1994 & 1995-1999 & 2000-2004 \\
\hline Number of articles & 135 & 212 & 300 & 310 & 344 \\
\hline \multicolumn{6}{|l|}{ Number of pages } \\
\hline Average & 13.5 & 13.9 & 15.0 & 17.0 & 17.3 \\
\hline Minimum & 2 & 3 & 2 & 1 & 3 \\
\hline 25th percentile & 11 & 11 & 12 & 13 & 13 \\
\hline Median & 14 & 14 & 15 & 17 & 18 \\
\hline 75th percentile & 16 & 17 & 18 & 21 & 21 \\
\hline Maximum & 27 & 29 & 33 & 34 & 34 \\
\hline Standard deviation & 4.7 & 4.6 & 5.2 & 6.3 & 5.9 \\
\hline \multicolumn{6}{|c|}{ Number of references } \\
\hline Average & 25.9 & 41.6 & 49.8 & 60.8 & 63.1 \\
\hline Minimum & 0 & 0 & 0 & 0 & 6 \\
\hline 25th percentile & 14 & 22 & 29 & 40 & 41 \\
\hline Median & 22 & 37 & 47 & 59 & 62 \\
\hline 75th percentile & 34 & 55 & 66 & 75 & 81 \\
\hline Maximum & 127 & 239 & 263 & 197 & 172 \\
\hline Standard deviation & 18.8 & 26.8 & 30.0 & 30.2 & 27.7 \\
\hline \multicolumn{6}{|l|}{ Number of authors } \\
\hline Average & 1.50 & 1.68 & 1.88 & 1.95 & 2.09 \\
\hline Minimum & 1 & 1 & 1 & 1 & 1 \\
\hline 25th percentile & 1 & 1 & 1 & 1 & 2 \\
\hline Median & 1 & 2 & 2 & 2 & 2 \\
\hline 75th percentile & 2 & 2 & 2 & 2 & 3 \\
\hline Maximum & 3 & 4 & 5 & 7 & 5 \\
\hline Standard deviation & 0.62 & 0.71 & 0.80 & 0.84 & 0.81 \\
\hline
\end{tabular}

\section{CONCLUSIONS}

The purpose of this article was to provide the first study of the maturing field of strategy research via analyses of changes in research topics and article characteristics. To this end we analyzed the trends in two major strategy journals- $L R P$ and SMJ-over a 25-year period between 1980-2004. Our analysis of research concepts and topics revealed the initial dominance (in the 1980s) of content and process categories—reflecting early interest in understanding different types of strategies 
(content) and how they are formed (process). Once a basis of understanding for these relatively basic topics was achieved, we noticed their subsequent decline in relative importance. On the other hand, the categories on the ascendance through the 1990s and early 2000s were the resource-based view of the firm and organizational forms. There is also some evidence in our data of swings between internal and external views of strategy as mentioned by other authors (Hoskisson, et al., 1999; Rumelt et al., 1994). And, as would be expected in a maturing research fields, we also identify trends towards longer articles, more references per article, and more coauthors, and provide several ideas why these changes might have occurred.

Limitations of this study include, as we explained above, exclusion of strategy articles that appeared in general management journals. This decision eliminated the need to decide whether each article in these diverse journals deals sufficiently with strategy research or not—a series of difficult and potentially arbitrary decisions. Nevertheless, the fact that much strategy research is published in general management journals and these are not covered in our study is a limitation that we should bear in mind. Another limitation is that our methodology entailed classifying all strategy research into seven quite broad areas, thus potentially missing more specific topics-for example, those mentioned in Table 1, like competitive strategy, diversification, and acquisitions. Also, we looked only at the most-cited articles. Thus, one should remember that those parts of the study that are related to the topics of strategy research are based on these highly-cited articles and not on all articles published by LRP and SMJ during 1980-2004. A study that includes a larger sample of articles with a less stringent criterion for inclusion than we employed will require much work but may yield some additional insights we could not obtain with our sample. Finally, the lack of authentication of the article classification mechanism is another limitation of this study (Azar \& Brock, 2010).

Future research should compare those areas of the strategy field that are underdeveloped relative to the needs of key constituents-like students at different levels and industrial consulting clients. Another idea for future research is to conduct studies similar to the research reported here, on other areas of strategy - as well as on other areas of management. A natural idea to be implemented in another decade or two is to re-examine the development of strategy research in light of the additional years of data available by that time. Finally, as implied above, research that looks at narrower, sub-areas of the strategy literature may be interesting to conduct in the future.

This article will improve the accessibility of strategy research to general 
managers. Those practitioners who are relatively familiar with strategy research will now be better able to appreciate how this young field has developed and should find it easier to identify streams of research relevant to their expertise. For example, managers concerned with planning systems will look to the "process" stream with a somewhat deeper appreciation; and those contemplating a joint venture can confidently narrow their search to the "organization type" area. For managers and prospective managers (including students of management) needing to explore strategy research for the first time, this article will help with an appreciation of the field's background and constituent streams. True, we only focus on two of the field's older journals, but these principles will apply to other strategy journals as well.

The young field of strategic management research clearly has come a long way in a short time. Articles published and referenced in the field's top journals-like LRP and $S M J$ - played a key part in establishing the field's legitimacy. We look forward to the time when more strategy journals like the Journal of Economics \& Management Strategy, and Strategic Organization have been listed in SSCI long enough to allow us to examine their development over time alongside $L R P$ and $S M J$.

\section{REFERENCES}

Azar, O. H. (2007). The slowdown in first-response times of economics journals: can it be beneficial? Economic Inquiry, 45(1), 179-187.

Azar, O. H., \& Brock, D. M. (2010). The development of strategy process research and the most influential articles and authors. In Kellermanns, Franz W., and Pietro Mazzola (Editors), Handbook of Strategy Process Research (pp. 3-21). Cheltenham, UK: Edward Elgar Publishing.

Boal, K. B., and Bryson, J. H. (1987). Representations, testing and policy implications of planning processes. Strategic Management Journal, 8(3), 211-231.

Dougherty, D. (2004). Organizing practices in services: capturing practice-based knowledge for innovation. Strategic Organization, 2(1), 35-64.

Doz, Y. L. (1996). The evolution of cooperation in strategic alliances: initial conditions or learning processes? Strategic Management Journal, 17(S1), 55-83.

Dyer, J. H., and Nobeoka, K. (2000). Creating and managing a high-performance knowledge-sharing network: the Toyota case. Strategic Management Journal, 21(3), 345-367.

Ellison, G. (2002a). The slowdown of the economics publishing process. Journal of Political Economy, 110(5), 947-993. 
Ellison, G. (2002b). Evolving standards for academic publishing: a q-r theory. Journal of Political Economy, 110(5), 994-1034.

Evered, R. (1983). So what is strategy? Long Range Planning, 16(3), 52-72.

Fahey, L., and Christensen, H. K. (1986). Evaluating the research on strategy content. Journal of Management, 12(2), 167-183.

Ginsberg, A., and Venkaraman, N. (1985). Contingency perspectives of organizational strategy: a critical review of the empirical research. Academy of Management Review, 10(3), 421-434.

Grant, R. (1996). Toward a knowledge-based theory of the firm. Strategic Management Journal, 17(Winter Special Issue), 109-122.

Gulati, R., Nohria, N., and Zaheer, A. (2000). Strategic networks. Strategic Management Journal, 21(3), 203-215.

Hambrick, D. C., and Chen, M-J. (2008). New academic fields as admittance-seeking social movements: the case of Strategic Management. Academy of Management Review, 33(1), 32-54.

Hoskisson, R. E., Hitt, M. A., Wan, W. P., and Yiu, D. (1999). Theory and research in strategic management: swings of a pendulum. Journal of Management, 25(3), 417-456.

Huff, A., and Reger, R. (1987). A review of strategic process research. Journal of Management, 13(2), 211-236.

ISI Web of Knowledge: Web of Science, Journal Citation Reports, Essential Science Indicators databases, available at http://apps.webofknowledge.com/.

Kipping, M., and Engwall, L. (2002). Management consulting: Emergence and dynamics of a knowledge industry. Oxford, UK: Oxford University Press.

Montgomery, C. A. (1988). Guest editor's introduction to the special issue on research in the content of strategy. Strategic Management Journal, 9(S1), 3-8.

Nag, R., Hambrick, D. C., and Chen, M-J. (2007). What is strategic management, really? Inductive derivation of a consensus definition of the field. Strategic Management Journal, 28(9), 935-955.

Phelan, S. E., Ferreira, M., and Salvador, R. (2002). The first twenty years of the Strategic Management Journal. Strategic Management Journal, 23(12), 1161-1168.

Porter, M. E. (1980). Competitive Strategy. New York: Free Press.

Prahalad, C. K., and Bettis, R. A. (1986). The dominant logic: a new linkage between diversity and performance. Strategic Management Journal, 7(6), 485-501. 
Ring, P. S., and Van de Ven, A. H. (1992). Structuring cooperative relations between organizations. Strategic Management Journal, 13(7), 483-498.

Rumelt, R. (1982). Diversification strategy and profitability. Strategic Management Journal, 3(4), 359-369.

Rumelt, R. P., Schendel, D., and Teece, D. J. (1994). Fundamental Issues in Strategy: A Research Agenda. Boston: Harvard Business School Press.

Summer, C. E., Bettis, R. A., Duhaime, I. H., Grant, J. H., Hambrick, D. C., Snow, C. C., and Zeithaml, C. P. (1990). Doctoral education in the field of business policy and strategy. Journal of Management, 16(2), 361-398.

Wernerfelt, B. (1984). A resource-based view of the firm. Strategic Management Journal, 5(2), 171-180. 
